\title{
Focus on Desorption Ionization and Macromolecular Mass Spectrometry
}

$\mathrm{I}$ $\mathrm{t}$ is difficult to determine who first introduced the term "Desorption" into the field of mass spectrometry. There is mention as early as 1954 in a few publications, particularly by Inghram and Gomer $[1,2]$. They did research with a field-ion microscope, and at least some of the observed ions came from gaseous atoms or small molecules adsorbed at the surface of the metal tip. It was H. D. Beckey, who in 1969 published a paper [3] that not only introduced the new technique of "Field Desorption" (FD), distinctly different from Müller's field ionization, but also connected this new ionization method to the "study of thermally unstable substances of low volatility". Interestingly, in field desorption, as in all ionization methods that later adopted the term "Desorption", the usage of the term is not correct because all these techniques generate ions from the bulk sample volume, rather than desorbing and ionizing molecules adsorbed at a surface.

To promote the subject of "desorption ionization," a series of meetings on DESORPTION began with one entitled "Ion Formation from Organic Solids" (IFOS) organized by Alfred Benninghoven in Münster, Germany, in 1980. Benninghoven had invented static Secondary Ion Mass Spectrometry (SIMS) and discovered its potential for the analysis of thermally unstable organic molecules of molecular weight ranging from several hundred to over a thousand Daltons. Five biennial conferences under the same title followed including IFOS IV in Münster in 1987 and a final one, IFOS V, in Lövanger, Sweden in 1989 [4-7].

The programs of these conferences accurately reflect the development of bioorganic mass spectrometry over that decade. Static SIMS was soon complemented by its sister technology, Fast Atom Bombardment (FAB), invented by $\mathrm{M}$. Barber and co-workers. Another major breakthrough came with the application of High-Energy, Heavy-IonInduced Desorption of molecules of biological interest. This technique, often referred to as ${ }^{252}$ Cf-Plasma Desorption, later simply called Plasma Desorption (PD) was invented in the mid 1970s by Ron Macfarlane and coworkers [8]. The spectrum of the small protein, insulin, was the first of a protein biomolecule to be recorded (Figure 1A). Even though the signal showing the molecular ion of the protein, presented by Sundqvist and coworkers of Uppsala University at the IFOS II meeting, was barely detectable, it nonetheless demonstrated that ions of such molecules could be generated, at least in principle. Of course, that was in contradiction to a common assumption of many mass spectrometrists of those days that protein ions were not stable out of solution and could not be introduced into the high vacuum of a mass spectrometer. The full impact of this discovery became apparent three years later at the IFOS III meeting, when the Uppsala group presented PD spectra of proteins, including trypsin of molecular weight $23 \mathrm{kDa}$, with greatly improved signal-to-noise ratio (Figure $1 \mathrm{~B}$ ).

It is interesting to note that many, if not most, of the participants of the early IFOS conferences and indeed the main players in the field of biomolecular mass spectrometry were physicists from nuclear, experimental and, as a rare exception, even from theoretical physics. This is because dramatically new methods were needed to generate ions of the labile and non-volatile compounds, methods typically developed in physics rather than (analytical) chemistry laboratories.

As time passed, the meetings became distinctly more interdisciplinary with attendance by scientists from physics, bio- and analytical chemistry and even biology, reflecting a transition from the development of new methods to their application, even though the emphasis remained on basic developments rather than pure applications. In this spirit, it is not a surprise that the first breakthrough from a barely visible insulin signal as shown in Fig. 1A to a real spectrum of trypsin shown in Fig. 1B was achieved, after a protein biochemist, Peter Roepstorff of Odense University (now University of Southern Denmark), joined the Uppsala group of physicists.

The first spectra of large proteins, obtained by Electrospray Ionization ESI [9], Matrix Assisted Laser Desorption Ionization MALDI [10] and "Soft Laser Desorption" [11] were published almost simultaneously in 1988. These events were the beginning of a real revolution in the field of macromolecular mass spectrometry, and the announcements had an almost immediate and dramatic impact on publications and conference programs, including that of the IFOS conference series. The programs of the major mass spectrometry conferences, notably the annual ASMS conferences and the triannual conferences of the International Mass Spectrometry Society (IMSC), soon included a large fraction of presentations and posters on ESI or MALDI. Quite expectedly, the emphasis was strongly on the wide range of applications of the new ionization methods.

Starting with the 1992 Conference in the castle of Waldeck, Germany, the IFOS Conference series continued under the new title of "DESORPTION [year]" 

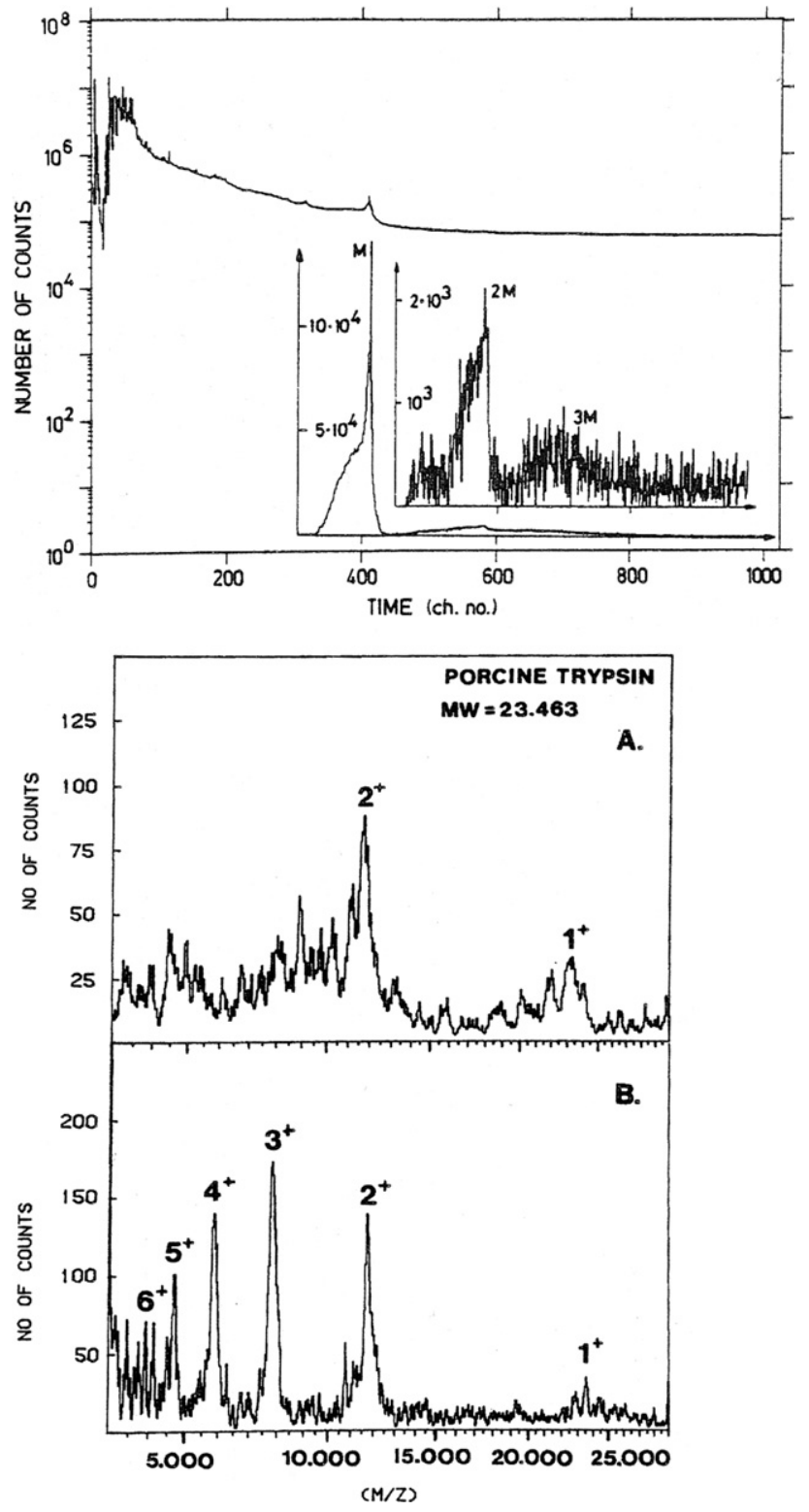

Figure 1. Plasma Desorption mass spectra of insulin (A) and trypsin (B). Adapted from refs. 4 and 5, respectively, with permission.

[12-18]. In contrast to the ASMS and IMSC conferences, the DESORPTION conferences, to a large extent, retained the original flavor, concentrating on mechanistic aspects, method development, and instrument development. Although a major emphasis was on MALDI, a "desorption ionization" method, ESI began to become part of the program such that by the time of the 2006 conference in Athens, ESI attracted approximately equal coverage, as shown in Figure 2.

The 1992 conference attracted as participants many who had significantly contributed to the development of the field and who continued to do so for many years to come (see Figure 3). Many of the essential steps in advancing the field of macromolec- ular mass spectrometry were discussed at these conferences, new ideas were spawned, and new collaborations established. Some ideas came and went because the expectations, associated with them, were not realized. Other ideas remained and grew, becoming an integral part of future conferences and an established part of the field. Over the years, a core group of participants became friends, with interactions beyond the strictly professional.

Recently, a new generation of scientists are attending the conference and will take over the field in the future. As an example, we show a photograph of the attendees of the 2006 meeting in Athens (Figure 4). The fields, "Desorption Ionization" and "Macromolecular Mass Spectrometry" and its DESORPTION conference are still active, and we expect them to grow in the future.

To commemorate the subject and its conference, we assembled a Focus in J. Am. Soc. Mass Spectrom. on the subject. The foundation for the focus is the DESORPTION 2006 conference from September 3-7, 2006, held at the Goulandris Natural History Museum in Kifissia, a suburb of Athens, and sponsored by the Museum. The meeting's organizer was Professor Dr. Anthony Tsarbopoulos of the University of Patras and the GAIA Research Center of the Goulandris Natural History Museum, along with Professor Dr. Michael Karas of the University of Frankfurt. It should be noted that DESORPTION 2006 was the first such meeting involved in mass spectrometry ever held in Greece. That not only reflects the relatively recent emergence of mass spectrometry related research activities in the country, but also indicates its expansive role within the country's biomedical science communities. The latter was shown by the recent formation of the Hellenic Mass Spectrometry Society. The relaxed atmosphere and the small size of the DESORPTION 2006 meeting provided the fertile grounds for fruitful discussions especially during the two workshops on electrospray and MALDI ionization processes. These late evening sessions were full of lively discussions on how aspects of mass spectrometry could be improved through a better understanding of the ionization process, thus enhancing its capability of providing solutions to problems from the macromolecular research area. The lively spirit of the meeting was maintained during the traditional conference excursion to the Cycladic island of Kea, which offered everyone a "taste" of the Aegean blue sea and sky combined with the experience of the ancient culture and art.

As a final note, we would like to acknowledge and thank the companies and organizations that sponsored that meeting: The Goulandris Natural History Museum, The Greek Secretariat for Research and Technology (AKMON 86), Thermo Electron, Schering-Plough Research Institute, Waters MALVA S.A., Biosolutions, Rigas Labs, Hellamco, Analytical Instruments, PharmaServe Lilly and Ktima Kiryanni 


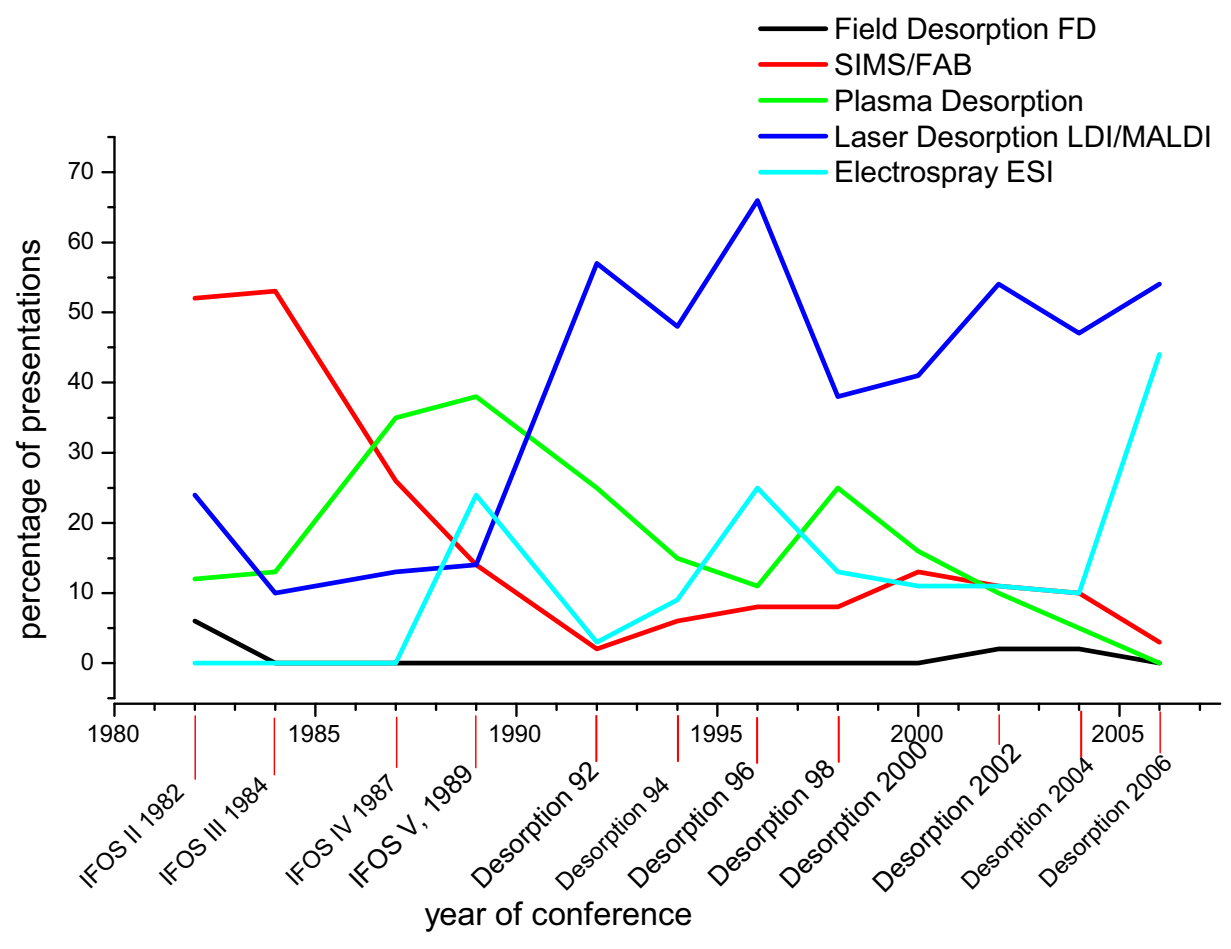

Figure 2. Representation of different ionization techniques discussed at the IFOS and DESORPTION conferences.

S.A. We would also like to express our thanks to people that so generously helped in the organization of the meeting, especially Fotini Bazoti, Evangelos Gikas and the stuff of T\&T Executive S.A.

We chose from papers presented at the conference, six papers to represent the joint themes of "Desorption Ionization" and "Macromolecular Mass Spectrometry". Those papers are:

"Top-Down Identification and Characterization of Biomolecules by Mass Spectrometry", Kathrin Breuker,
Mi Jin, Xuemei Han, Honghai Jiang, and Fred W. McLafferty

"Using Fluorescence Dyes as a Tool for Analyzing the MALDI Process", Thorsten W. Jaskolla and Michael Karas

"Nano ES GEMMA and PDMA, new tools for the analysis of nanobioparticles-protein complex, lipoparticles and virus", Günter Allmaier, Christian Laschober, and Wladyslaw W. Szymanski

"Enhancement of Protein Sensitivity for MALDI Im-

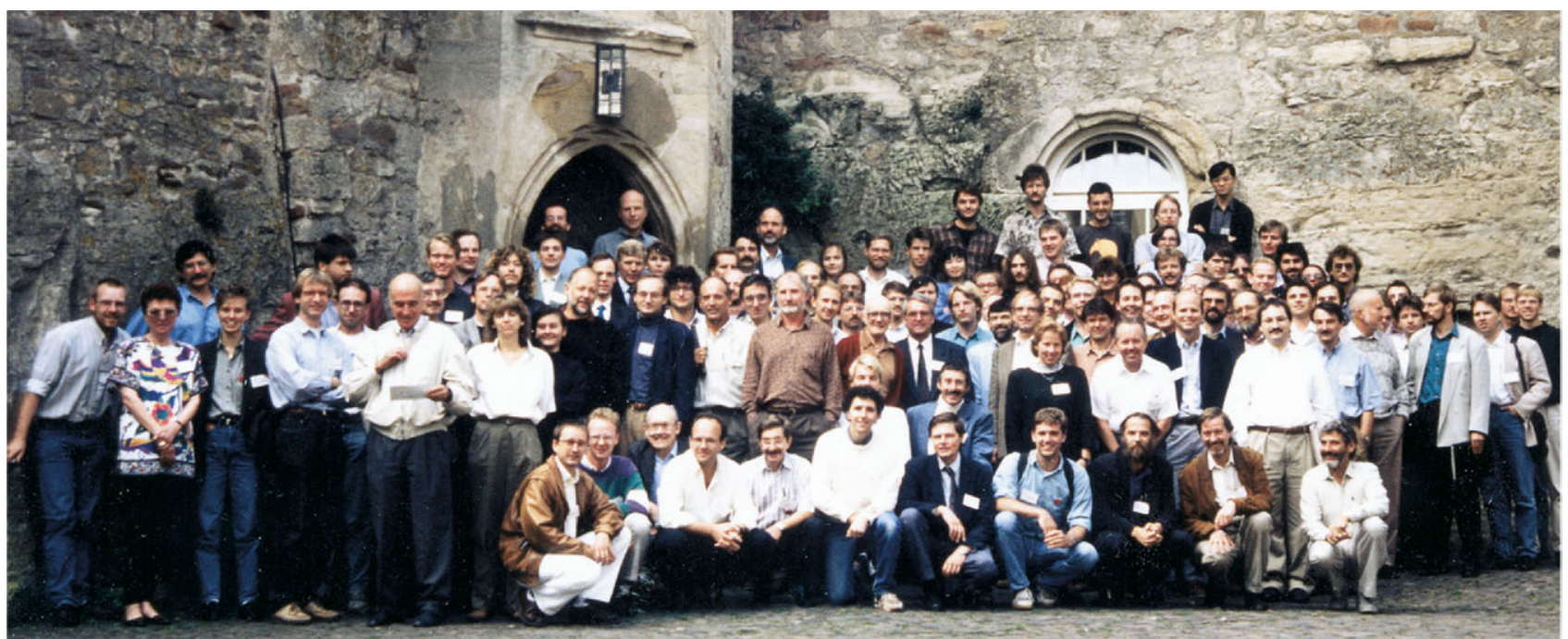

Figure 3. Participants at DESORPTION '92 conference, September 6-9, 1992, Burg Waldeck, Germany. 


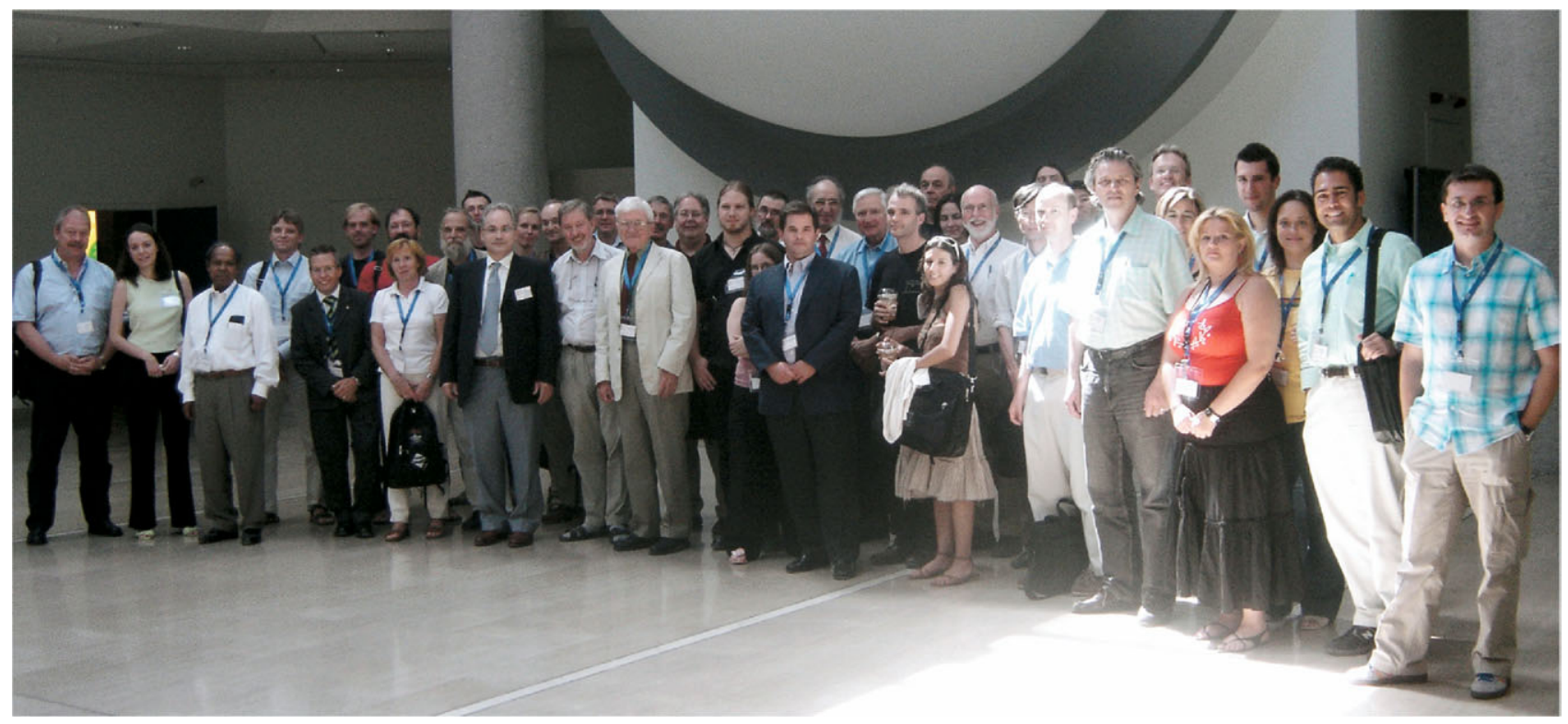

Figure 4. Participants at DESORPTION '06 conference, September 3-7, 2006, Goulandris Natural History Museum in Kifissia (Athens), Greece.

aging Mass Spectrometry After Chemical Treatment of Tissue Sections", Erin H. Seeley, Stacey R. Oppenheimer, Deming Mi, Pierre Chaurand, and Richard M. Caprioli

"Localization of the Noncovalent Binding Site Between Amyloid- $\beta$-Peptide and Oleuropein Using Electrospray Ionization FT-ICR Mass Spectrometry", Fotini N. Bazoti, Jonas Bergquist, Karin Markides, and Anthony Tsarbopoulos

"Improving the Signal Intensity and Sensitivity of MALDI Mass Spectrometry by Using Nanoliter Spots Deposited by Induction-based Fluidics", Tingting Tu, Andrew D. Sauter, Jr., Andrew D. Sauter, III, and Michael L. Gross

\section{Franz Hillenkamp} University of Münster Germany

Anthony Tsarbopoulos University of Patras and GAIA Research Center

Greece

Michael L. Gross, Editor-in-Chief Washington University USA

\section{Literature Cited:}

1. Mark G. Inghram and Robert Gomer, Mass Spectrometric Analysis of Ions from the Field Microscope, J. Chem. Phys. 22 (1954) 1279-1280.

2. Robert Gomer and Mark G. Inghram, Applications of Field Ionization to Mass Spectrometry, J. Am. Chem. Soc. 77 (1955) 500.
3. H. D. Beckey, Field desorption mass spectrometry: A technique for the study of thermally unstable substances of low volatility, J. Mass Spectrom and Ion Physics, 2 (1969) 500-502.

4. Ion Formation from Organic Solids, Springer Series in Chemical Physics, A. Benninghoven, ed., Springer Verlag, Berlin, Heidelberg, New York, Tokyo, 1983.

5. Ion Formation from Organic Solids, IFOS III, Springer Proceedings in Physics 9, A. Benninghoven, ed., Springer Verlag, Berlin, Heidelberg, New York, Tokyo, 1986.

6. Ion Formation from Organic Solids IV, A. Benninghoven, ed., John Wiley \& Sons, Chichester, New York, Brisbane, Toronto, Singapore, 1989.

7. Ion Formation from Organic Solids V, A. Hedin, B. U. R. Sundqvist and A. Benninghoven, eds., John Wiley \& Sons, Chichester, New York, Brisbane, Toronto, Singapore, 1990.

8. R. D: Macfarlane and D. F: Torgerson, Californium-252 plasma desorption mass spectroscopy, Science 191 (1976) 920-925.

9. J.B. Fenn, M. Mann, C.K. Meng, S.F. Wong, and C.M. Whitehouse, Electrospray ionization for mass spectrometry of large biomolecules, Science 246 (1989) 64-71.

10. Michael Karas and Franz Hillenkamp, Laser desorption ionization of proteins with molecular masses exceeding 10,000 daltons, Anal. Chem. 60 (1988) 2299-2301.

11. K. Tanaka, H. Waki, Y. Ido, S. Akita, Y. Yoshida, and T. Yoshida, Protein and Polymer Analyses up to mz 100000 by Laser Ionization Time-ofFlight Mass Spectrometry, Rapid Commun. Mass Spectrom. 2, (1988) 151-153.

12. Book of Abstracts of the Desorption '92 conference, Burg Waldeck, Germany, September 6-9, 1992.

13. Book of Abstracts of the Desorption '94 conference, Sun River Lodge, OR, USA, March 6-9, 1994.

14. Book of Abstracts of the Desorption '96 conference, Rönne, Bornholm, Denmark, Sept. 18-21, 1996

15. Book of Abstracts of the Desorption '98 conference, Rio de Janeiro, Brazil, Sept. 21-26, 1998.

16. Book of Abstracts of the Desorption 2000 conference, Saint Malo, France, Sept. 3-7, 2000

17. Book of Abstracts of the Desorption 2002 conference, Estes Park, CO, USA, Sept. 1-5, 2002.

18. Book of Abstracts of the Desorption 2004 conference, St. Petersburg, Russia, Aug. 29-Sept. 2, 2004 